\title{
La controverse sur les effets des faibles doses de rayonnements ionisants et la relation linéaire sans seuil
}

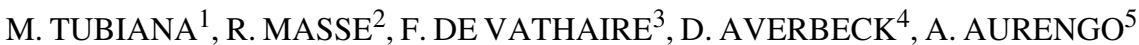

(Manuscrit reçu le 11 août 2006, accepté le 18 février 2007)

RÉSUMÉ

Si la publication 99 de la CIPR et le BEIR VII recommandent de maintenir l'usage d'une relation linéaire sans seuil (RLSS) pour estimer l'excès de risque relatif de cancer lié à de faibles doses de rayonnements ionisants (RI), le rapport conjoint de l'Académie des sciences et de l'Académie de médecine (2005) conclut qu'elle conduit à une forte surestimation des risques des faibles et des très faibles doses. Les fondements de la RLSS sont remis en question par de nouvelles données biologiques et de l'expérimentation animale qui montrent que la défense contre les RI met en jeu le micro-environnement cellulaire et le système immunitaire, et que les mécanismes de défense contre les faibles doses de RI sont différents et plus efficaces. Ces cellules lésées par une irradiation à faible dose sont éliminées ; la réparation s'impose à forte dose pour préserver les fonctions tissulaires. Les organismes pluricellulaires réalisent ainsi une défense au moindre coût et au moindre risque contre les RI et les dégâts du métabolisme oxydatif. Les différences entre les défenses contre les faibles et fortes doses sont particulièrement nettes dans le cas de contamination par des émetteurs alpha qui montrent chez l'homme et l'animal des effets à seuil de plusieurs grays. Ces différences remettent en question les résultats des études épidémiologiques qui, pour des raisons de puissance statistique, estiment les risques en fusionnant des données obtenues pour des gammes de doses très étendues, ce qui sous entend implicitement que les mécanismes de cancérogenèse sont similaires quelle que soit la dose. L'estimation des risques des faibles doses de RI doit reposer sur des études spécifiquement limitées aux faibles doses, avec une évaluation précise de facteurs de confusion potentiels. La synthèse des études de cohorte pour lesquelles on dispose des coefficients de risque fondés sur les seules doses inférieures à $100 \mathrm{mSv}$ chez l'adulte ne montre pas d'excès de risque relatif significatif, ni pour les tumeurs solides ni pour les leucémies.

ABSTRACT The risk of low doses of ionising radiation and the linear no threshold relationship debate.

The ICRP and the BEIR VII reports recommend a linear no threshold (LNT) relationship for the estimation of cancer excess risk induced by ionising radiations (IR), but the 2005 report of Medicine and Science French Academies concludes that it leads to overestimate of risk for low and very low doses. The bases of LNT are challenged by recent biological and animal experimental studies which show that the

\footnotetext{
Faculté de Médecine, Centre Antoine Béclère, 45 rue des Saints-Pères, 75006 Paris, France.

11 rue du Haras, Résidence Le Boqueteau, Acacias 2, 91240 Saint-Michel-sur-Orge, France.

INSERM U 605. Institut Gustave Roussy, 39 rue Camille Desmoulins, 94805 Villejuif Cedex, France.

Institut Curie, Section de Recherche, Laboratoire Raymond Latarjet, UMR2027 du CNRS, Centre Universitaire d'Orsay, 91405 Orsay Cedex, France.

5 Service Médecine Nucléaire, Hôpital Pitié-Salpêtrière, 75013 Paris, France.
} 


\begin{abstract}
defence against IR involves the cell microenvironment and the immunologic system. The defence mechanisms against low doses are different and comparatively more effective than for high doses. Cell death is predominant against low doses. DNA repairing is activated against high doses, in order to preserve tissue functions. These mechanisms provide for multicellular organisms an effective and low cost defence system. The differences between low and high doses defence mechanisms are obvious for alpha emitters which show several greys threshold effects. These differences result in an impairment of epidemiological studies which, for statistical power purpose, amalgamate high and low doses exposure data, since it would imply that cancer IR induction and defence mechanisms are similar in both cases. Low IR dose risk estimates should rely on specific epidemiological studies restricted to low dose exposures and taking precisely into account potential confounding factors. The preliminary synthesis of cohort studies for which low dose data $(<100 \mathrm{mSv})$ were available show no significant risk excess, neither for solid cancer nor for leukemias.
\end{abstract}

Keywords: low doses / linear no threshold relationship / cancer / leukemia / radioinduced

\title{
1. Introduction
}

En 2005, trois rapports sur les effets des faibles doses et la relation dose-effet des rayonnements ionisants ont été publiés : le rapport conjoint de l'Académie des sciences et de l'Académie de médecine (Tubiana et al., 2005), le BEIR VII (2005) et la publication 99 de la CIPR (ICRP, 2005). Bien qu'ils s'appuient dans l'ensemble sur les mêmes publications, ces rapports aboutissent à des conclusions différentes. La CIPR et le BEIR recommandent de maintenir l'usage de la relation linéaire sans seuil (RLSS) pour estimer l'effet cancérogène des faibles ( $<100 \mathrm{mSv}$ ) et très faibles doses $(<10 \mathrm{mSv})$ de rayonnements ionisants. Au contraire le rapport conjoint des académies conclut que l'utilisation de la RLSS est susceptible d'entraîner une forte surestimation des risques des faibles et surtout des très faibles doses. Un an après la parution de ces rapports, l'objet de cet article est de faire le point sur les divers aspects de ce débat auquel plusieurs articles et un symposium ont été consacrés (Brenner et Sachs, 2006 ; Tubiana et al., 2006a, 2006b ; Meeting report, 2006) et de rechercher comment on pourrait progresser.

Pour quantifier l'excès de risque relatif (ERR) de cancer induit par une exposition aux rayonnements ionisants, une relation linéaire sans seuil (RLSS) entre la dose et l'ERR a été introduite dans les années 1960 pour des raisons non pas scientifiques mais administratives, afin de simplifier la radioprotection en rendant possible l'addition de doses délivrées dans des conditions très diverses. On lui a trouvé un soubassement théorique quand, à la fin des années 1970, on a montré le rôle des mutations dans la cancérogenèse (en activant un gène normal en un oncogène, ou en inactivant un gène suppresseur). Comme on croyait alors que la fréquence des mutations obéissait à une relation linéaire sans seuil et que la cancérogenèse était un phénomène stochastique, la RLSS acquit le statut d'un fait scientifique prouvé par le raisonnement suivant : lors d'une irradiation, toute dose est délivrée à l'échelle de la cellule par le passage d'un nombre proportionnel 
d'électrons agissant de manière indépendante. Le passage de chaque électron dans le noyau d'une cellule peut entraîner un dépôt d'énergie suffisant pour causer des lésions graves de l'ADN, telle une cassure double-brins. Donc toute dose peut causer une mutation avec une probabilité proportionnelle au nombre d'électrons traversant le noyau, donc à la dose. On peut en déduire que la probabilité de cancérogenèse est proportionnelle à la dose. C'est ce qui a été appelé l'argument dosimétrique.

L'adoption de la RLSS semblait donc avoir été un coup de génie prémonitoire ; elle devint un dogme. Cependant, trois raisons expliquent qu'on mette aujourd'hui en doute sa validité :

1. malgré tous les efforts effectués, il a été impossible de mettre en évidence, chez l'homme adulte, un excès significatif de cancer pour des doses inférieures à environ $100 \mathrm{mSv}$. Pour les tumeurs solides chez les survivants des bombes atomiques, la relation dose-effet paraissait linéaire (contrairement au cas des leucémies), mais les dernières publications (Preston et al., 2004) montrent qu'en tenant compte d'un plus long recul et de la révision dosimétrique, cette relation n'est pas linéaire et présente une inflexion pour des doses de l'ordre de plusieurs centaines de $\mathrm{mSv}$ sans que l'existence d'un effet cancérogène pour des doses inférieures à $100 \mathrm{mSv}$ ait pu être établie ;

2. chez l'animal, on n'observe pratiquement jamais de relation linéaire mais des relations linéaires-quadratiques ou curvilinéaires, avec un seuil apparent ou même un effet d'hormésis, c'est-à-dire une diminution de la fréquence naturelle des cancers après irradiation après de très faibles doses (comme pour l'incidence des leucémies chez les survivants des bombes);

3. les progrès de la radiobiologie ont montré que les cellules ne subissent pas passivement les dommages infligés par l'irradiation mais se défendent par des mécanismes cellulaires et tissulaires. Si le nombre de lésions initiales est bien proportionnel à la dose, ces mécanismes sont différents à faible et forte dose, ce qui induit de fortes non-linéarités entre dose et débit de dose et le risque final de cancérisation.

Devant cette situation, les deux académies ont créé en 2003 un groupe de travail commun pour étudier ce problème qui est d'une grande importance médicale en raison des conséquences éventuelles que pourraient entraîner l'utilisation médicale des rayonnements ionisants si la RLSS était valable dans la gamme des doses délivrées en radiodiagnostic ( 1 à $20 \mathrm{mSv}$ ).

\section{Mécanismes de défense biologiques}

À l'époque où la RLSS a été proposée, et jusqu'en 1980, on ignorait ou on sousestimait la puissance des mécanismes de défense contre les rayonnements. Ces 
mécanismes sont le fruit de l'adaptation acquise par l'évolution avec la nécessité pour les eucaryotes de résister aux radicaux générés par leur propre métabolisme oxydatif. Ces radicaux contribuent journellement, dans chaque cellule, à plusieurs milliers de lésions de l'ADN dont 8 à 50 cassures doubles brins (Vilenchik et Knudson, 2003). Les conséquences de l'exposition aux rayonnements ionisants sont traitées de la même manière que ces lésions spontanées. Seules les lésions multiples (LDMS) semblaient présenter une spécificité, cependant les travaux récents (Averbeck, 2007 ; Averbeck et al., 2006) montrent qu'elles ne sont que marginalement doses dépendantes et que leur évolution est essentiellement létale, ce qui leur confère très peu d'impact sur la mutagenèse et la cancérogenèse. Nous savons maintenant qu'il existe trois principaux systèmes de défense à l'échelle de la cellule, dont la mise en jeu dépend de la dose et du débit de dose.

1. Le stress oxydatif provoqué par l'irradiation induit des mécanismes contre les agents d'oxydation, tels les radicaux libres et plus généralement les espèces actives de l'oxygène. L'efficacité de ces mécanismes (agents de réduction tels le glutathion, ou enzymes détruisant les agents d'oxydation) est plus grande à faible dose et contribue à diminuer le taux de lésions spontanés ou induits dans l'ADN (De Toledo et al., 2006).

2. La réparation de l'ADN. Dans les cellules, des systèmes de détection des lésions cheminent constamment le long des molécules d'ADN et vérifient leur intégrité. En cas de lésion, ils activent deux protéines impliquées dans le syndrome humain d'ataxie télangiectasie, l'ataxia telangiectasia mutated (ATM) et l'ATM- and Rad3-related (ATR), qui jouent un rôle clé dans la signalisation du système de sauvegarde, lequel recouvre un grand nombre de mécanismes très voisins, de la levure à l'homme (Bakkenist et Kastan, 2004). La cellule peut être tuée par des lésions irréparables, mais les mutations apparaissent, dans l'immense majorité des cas, du fait des erreurs commises pendant la réparation de l'ADN (Averbeck, 2000).

Quand la dose (ou le débit de dose) augmente, le nombre de lésions présentes simultanément dans la cellule augmente et la probabilité de réparation fautive augmente (Dikomey et Brammer, 2000 ; Boucher et al., 2004). Ce phénomène pourrait être lié à une difficulté d'intervention des systèmes de réparation quand les lésions simultanément présentes dans une cellule sont nombreuses. De plus la prolifération cellulaire interfère avec la réparation des cellules. Elle est stimulée par des doses supérieures à quelques centaines de mGy qui entraînent une mortalité cellulaire notable.

Contrairement à ce qui était un des dogmes de la radiobiologie, à dose égale, la probabilité de mutation varie avec le débit de dose, selon une relation 
parabolique en fonction du logarithme du débit de dose (Vilenchik et Knudson, 2006, 2000). Pour les mutations chromosomiques, l'effet mutagène d'une même dose est beaucoup plus petit à faible débit qu'à haut débit (Loucas et al., 2004). Cette variation est due à la réparation de l'ADN car, quand la réparation est bloquée (par exemple à faible température ou après administration d'agents chimiques) ou absente (sujets congénitalement déficients en système de réparation), on n'observe pas de diminution de l'effet létal ou mutagène à faible débit. Vilenchik et Knudson (2006) supposent que ces données sont liées à un phénomène physiologique (signaling resonance) selon lequel les signaux cellulaires résultant de cassures double brins entraîneraient des réponses d'efficacité maximale quand elles sont produites à un taux voisin de celui de leur production endogène.

D'autres phénomènes montrent que la probabilité de réparation fidèle des lésions de l'ADN est modulée par plusieurs facteurs.

- Pour des doses inférieures à 200 mSv, l'effet létal par unité de dose est plus grand (et l'effet mutagène plus faible puisque les cellules dont l'ADN a été lésé meurent davantage). Lors d'une irradiation continue, ce phénomène d'hypersensibilité disparaît pour des doses supérieures à $500 \mathrm{mSv}$, ce qui parait dû à l'activation de certains systèmes de réparation dans lesquels l'enzyme proteolytic poly (ADP-ribose) polymerase (PARP) joue un rôle (Marples et al., 2004 ; Chalmers et al., 2004). Cette disparition de l'hypersensibilité ne s'observe pas si l'on administre de l'aminobenzamide qui inhibe la PARP.

- Après une irradiation courte et intense, on observe des variations rapides et brutales de la radiosensibilité des cellules survivantes dans lesquelles des mécanismes enzymatiques sont impliqués (Fernet et al., 2000 ; Ponette et al., 2000).

- Après une première irradiation à faible dose, la radiosensibilité in vivo et in vitro est plus faible. Ce phénomène d'adaptation est maintenant bien établi (Rigaud et Moustacchi, 1996) et l'on commence à en comprendre les mécanismes (Bravard et al., 1999).

3. La mort des cellules dont l'ADN a été lésé est le troisième mécanisme de sauvegarde, la mort d'une petite proportion de cellules dans un organisme multicellulaire pouvant être facilement compensée.

En l'absence d'activation des systèmes de réparation de l'ADN, via la signalisation intracellulaire, la réparation est peu efficace et les cellules lésées meurent. Or deux séries d'expériences (Rothkamm et Löbrich, 2003 ; Collis et al., 2004) montrent que les très faibles doses et débits de dose ne provoquent 
pas cette activation. Dans ces expériences, après irradiation, on observe initialement une relation linéaire entre la dose et le nombre de cassures doubles brins de l'ADN. Mais si la dose est faible (quelques $\mathrm{mSv}$ ) on ne décèle pas de réparation de l'ADN et, après mise en culture, le nombre de cellules porteuses de cassures doubles brins revient à la normale. L'apoptose (ou mort programmée) et d'autres modalités de mort cellulaire sont provoquées par une irradiation avec une fréquence qui dépend de la dose et du débit de dose. Elles débarrassent l'organisme d'une proportion variable de cellules lésées; l'efficacité de ce mécanisme protecteur plafonne et diminue pour des doses supérieures à $200 \mathrm{mSv}$.

À ces mécanismes de base s'ajoutent d'autres voies possibles permettant d'inhiber l'évolution des cellules potentiellement initiées, notamment la différenciation (Belyakov et al., 2006) et l'évolution vers la sénescence cellulaire dont les $\mathrm{CDB}$ non réparées sont des inducteurs (Bartkova et al., 2006) qui concurrencent l'apoptose (Roos et Kaina, 2006).

Ces différences essentielles entre les mécanismes de défense contre les RI selon la dose, sont confirmées par des études effectuées avec des puces à ADN qui montrent que même après de très faibles doses, il y a modification de la transcription d'un nombre important de gènes, mais que selon la dose ces modifications ne concernent pas les mêmes gènes. Cela suggère l'existence de plusieurs stratégies de défense en fonction de la dose et du débit de dose (Bishay et al., 2001 ; Amundson et al., 2003 ; Mercier et al., 2004 ; Franco et al., 2005). Il est particulièrement intéressant d'observer qu'après une dose élevée (2 Gy), l'expression de plusieurs centaines de gènes est modifiée environ 3 heures après exposition. Une dose de $10 \mathrm{mGy}$ induit des réactions différentes, elle ne modifie pas l'expression des gènes pendant les premières heures mais seulement après 48 h. Une centaine de gènes spécifiques aux faibles doses ont alors leur expression modifiée, ce que montre également l'étude du protéome (Menard et al., 2006 ; Yang et al., 2006). Ces différences qualitatives et temporelles confirment que le type de réaction biologique varie fortement avec la dose (Franco et al., 2005).

Ainsi l'ensemble des données expérimentales montre une grande variation de l'efficacité des systèmes de réparation en fonction de la dose ou du débit de dose. Cette variation relève de plusieurs mécanismes (activation des systèmes de réparation, arrêt temporaire du cycle cellulaire, rôle du nombre de lésions simultanément présentes, etc.).

Tout se passe donc comme si les organismes pluricellulaires avaient développé une stratégie de défense au moindre coût et au moindre risque contre les 
rayonnements ionisants et les espèces actives de l'oxygène résultant du métabolisme oxydatif :

- après des faibles doses ou lors d'irradiations a faible débit de dose, le mécanisme de défense prédominant, très efficace, est l'élimination des cellules potentiellement dangereuses dont l'ADN a été lésé, soit faute d'activation des systèmes de réparation de l'ADN, soit par apoptose ;

- au contraire, après des doses supérieures à environ $200 \mathrm{mSv}$, la réparation de l'ADN devient le phénomène prédominant. Dans ce cas, en effet, l'élimination des cellules dont l'ADN a été lésé venant s'ajouter à l'effet létal de l'irradiation pourrait causer de graves lésions tissulaires et mettre en cause le fonctionnement de l'organisme. Le risque de cancer est alors le prix à payer pour assurer la sauvegarde fonctionnelle tissulaire (Tubiana et al., 2005) d'autant que le risque de réparation fautive et donc de mutation augmente avec la dose (Dikomey et Brammer, 2000).

En résumé, les mécanismes de défense contre les mutations de la cancérogenèse sont proportionnellement plus efficaces à faible dose qu'à forte dose. Ces données montrent qu'on ne peut pas admettre l'hypothèse d'un risque génotoxique par unité de dose constant quels que soient la dose ou le débit de dose. Ceci contredit les postulats sur lesquels repose la RLSS mais ne signifie pas que ces mécanismes sont infaillibles à faible dose. Alors que le rapport conjoint accorde une grande signification à ces variations de l'efficacité des systèmes de réparation, le rapport BEIR VII cite ces travaux mais ne prend pas en compte leurs implications.

\section{Mécanismes de défense tissulaires}

La RLSS implique que la probabilité d'apparition d'une altération potentiellement cancérogène du génome par unité de dose est indépendante de la dose et du débit de dose, mais également que le développement de cette altération pour aboutir à une cellule maligne ne dépend pas d'éventuelles autres lésions dans la même cellule et/ou les cellules voisines.

Cette hypothèse est en opposition avec nos connaissances actuelles sur la cancérogenèse. L'étude expérimentale de la radiocancérogenèse depuis plusieurs décennies montre que l'émergence d'un cancer nécessite au moins deux phases : l'initiation d'une cellule, liée à une modification de son génome (génétique ou épigénétique) et la promotion qui est la conséquence de nouvelles modifications de la cellule initiée apparues au cours de sa prolifération et qui la rend autonome par rapport aux cellules environnantes. La probabilité d'induction d'une tumeur est donc le produit de 2 probabilités. Les RI peuvent agir à la fois comme initiateur et comme promoteur quand la dose a été suffisamment forte pour tuer une proportion importante de cellules et causer une prolifération compensatrice. 
L'influence de la prolifération a été mise en évidence chez l'animal depuis des décennies dans de nombreuses expériences (UNSCEAR, 2000) : par exemple la probabilité d'induction de cancer de l'ovaire et de la mamelle est augmentée, après irradiation, par l'administration d'œstrogène, celle du rein irradié par néphrectomie unilatérale qui cause une hypertrophie du rein restant. L'irradiation des souris BALB/C pour une dose de 1 Gy induit un cancer chez $14 \%$ des souris. $\mathrm{Si}$ le tissu mammaire est excisé, et les cellules dissociées et greffées dans la rate, des tumeurs apparaissent en grand nombre mais ce nombre est limité si les cellules irradiées sont injectées en même temps que des cellules mammaires non irradiées (Kamiya et al., 1995). Chez l'homme, l'incidence des cancers de la peau après irradiation est plus grande dans les populations à peau blanche qu'à peau colorée à cause des morts cellulaires causées par les ultraviolets solaires qui entraînent une amplification clonale (Brash, 1997).

Ce rôle des mécanismes de régulation de la prolifération est donc bien connu (UNSCEAR, 2000). Le fait nouveau est la mise en évidence du rôle des interactions cellulaires et de diverses cytokines au cours de ce processus (Radisky et Bissell, 2004 ; Mueller et Fusening, 2004 ; Bhowmick et al., 2004 ; BarcellosHoff, 2005). La cancérogenèse se heurte à des systèmes de défense tissulaires qui correspondent à ceux qui régissent l'embryogenèse et la régénération d'un tissu après une agression (Beachy et al., 2004). La probabilité d'échappement d'une cellule initiée, et donc d'émergence d'un cancer, est plus grande quand le tissu a été désorganisé, en particulier quand la proportion de cellules lésées ou tuées est élevée. À dose égale, une irradiation homogène est plus cancérogène qu'une irradiation hétérogène, à travers une grille par exemple (Burns et Albert, 1986), dans laquelle les cellules irradiées sont en contact avec des cellules non irradiées ou irradiées à dose faible.

De même les données expérimentales et humaines observées après contamination par des radioéléments émetteurs $\alpha$ (radium ou thorium) montrent que ces contaminations ne provoquent pas de cancer pour des doses inférieures à quelques Gy chez l'homme ou l'animal, et que pour des doses plus élevées la fréquence des cancers induits s'accroît brutalement (Carnes et al., 1997). L'existence d'un seuil est indiscutable pour les ostéosarcomes observés chez les peintres de cadrans lumineux contaminés par la peinture au radium et les cancers du foie observés chez les malades auxquels on avait injecté du thorotrast (Van Kaick et al., 1991). Dans les deux cas, les cellules irradiées sont peu nombreuses et reçoivent des doses d'environ $400 \mathrm{mGy}$, et elles sont entourées de cellules saines non irradiées. Quand la dose totale augmente, la dose absorbée dans les cellules irradiées varie peu : c'est celle délivrée lors de la traversée d'une cellule par une particule $\alpha$. En revanche, la proportion de cellules ayant été traversées par une particule $\alpha$ par unité de temps augmente avec la dose. Deux mécanismes non 
mutuellement exclusifs peuvent alors expliquer le seuil constaté : (i) les cellules irradiées réparent les lésions, ou meurent quand elles ne sont traversées que par une particule $\alpha$ (Miller et al., 1999), (ii) leur prolifération est contrôlée par les cellules saines qui les entourent (Tubiana, 2003). Dans les deux cas, le seuil observé est incompatible avec une RLSS. Comme une particule $\alpha$ a une efficacité cancérogène très supérieure à celle d'un électron, ces résultats montrent la puissance des mécanismes de défense tissulaires.

Les systèmes de surveillance mis en œuvre par les cellules saines de l'organisme sont capables d'éliminer des clones de cellules transformées, comme le montrent les échecs des greffes de cellules tumorales ainsi que la forte augmentation de la fréquence de certains cancers chez les sujets immunodéprimés (Euvrard et al., 2003). Un lien semble exister entre une déficience du système de réparation NHEJ et l'immunodéficience.

Enfin, l'apoptose des cellules dont l'ADN est lésé est stimulée par l'exposition des cellules saines qui les entourent à de faibles doses de RI (Portess et al., 2007). Ce résultat très récent pourrait contribuer à expliquer les phénomènes d'hormésis.

\section{Apports et limites de l'épidémiologie}

Pour des doses supérieures à $200 \mathrm{mSv}$ environ, les données de l'épidémiologie permettent d'apprécier la relation dose-effet avec une relative précision. En revanche, pour des faibles doses et a fortiori pour les très faibles doses, l'épidémiologie ne peut ni affirmer l'existence d'un excès de cancer, ni exclure son éventualité. Elle montre cependant que ce risque, s'il existe, est faible. Ces études ne décèlent aucun effet pour des doses inférieures à environ 100-200 mSv chez l'adulte et $80-100 \mathrm{mSv}$ chez l'enfant, soit qu'il n'en existe pas, soit que la puissance statistique des enquêtes ait été insuffisante pour les détecter.

Les données épidémiologiques proviennent de quatre sources.

\section{Les survivants des bombardements d'Hiroshima et Nagasaki (HN)}

Pour les leucémies radio-induites, la relation dose-effet est statistiquement incompatible avec une RLSS et montre un seuil à environ $150 \mathrm{mSv}$ et une diminution du risque spontané (hormésis ?) pour les doses inférieures à 100 mSv (Little et Muirhead, 1996, 2000). Pour les tumeurs solides, la dernière analyse, qui prend en compte l'allongement du suivi et la révision de la dosimétrie en 2002 (Katayama et al., 2002), montre une inflexion dans la relation dose effet (entre 0,5 et $1 \mathrm{~Gy}$ ), incompatible avec la linéarité (Preston et al., 2004). 


\section{Les irradiations professionnelles ou post-accidentelles}

La plupart de ces études montrent que les faibles doses, délivrées à faible ou à fort débit, n'ont soit aucun effet statistiquement significatif sur la mortalité ou l'incidence des cancers, soit des effets nettement plus faibles que ceux calculés à partir des données du suivi des survivants des bombes atomiques (HN).

Les données obtenues avec les 21500 travailleurs du complexe de Mayak montrent, pour les cancers solides, un excès de risque relatif de décès par sievert de 0,15 (90\% CI : 0,09-0,20), inférieur à celui observé sur la cohorte HN, mais la dosimétrie est assez imprécise (Shilnikova et al., 2003).

Une étude sur 8600 liquidateurs de l'accident de Tchernobyl (dose moyenne : $50 \mathrm{mSv}$ ) montre une sous-incidence significative de $12 \%$ de l'ensemble des cancers par rapport la population générale russe, et n'a pas permis de mettre en évidence de relation dose-effet significative (Ivanov et al., 2004). De même l'analyse de l'incidence des leucémies chez ces liquidateurs n'a pas montré d'accroissement de la fréquence des leucémies et des tumeurs solides. Ces observations ne confirment pas les prédictions qui avaient été faites, au moins en ce qui concerne les leucémies dont le délai d'apparition est court, alors que les doses reçues par la population peuvent atteindre $100 \mathrm{mSv}$ et celles des liquidateurs sont en moyenne de $100 \mathrm{mSv}$ mais dépassent $300 \mathrm{mSv}$ chez $5 \%$ des liquidateurs (Cardis et al., 2006). Chez les enfants irradiés à Tchernobyl une augmentation de la fréquence des cancers du corps thyroïde n'a été observée que pour des doses supérieures à $200 \mathrm{mSv}$ (Cardis et al., 2005a). Le travail initial suggérait une relation dose-effet linéaire mais Scott (2006) a montré, et ceci n'a pas été contesté par Cardis et al., que l'analyse des données ne permet pas d'exclure l'absence d'effet des doses inférieures à $200 \mathrm{mSv}$, voire un effet d'hormésis.

La méta-analyse du CIRC portant sur 96000 travailleurs du nucléaire (Cardis et al., 1995) avait montré un risque de mort par leucémie pour des doses supérieures à $400 \mathrm{mSv}$ (deux fois inférieur aux estimations de HN) et l'absence d'augmentation significative des décès par tumeur solide. La nouvelle étude internationale de mortalité par cancer des travailleurs de l'industrie nucléaire (Cardis et al., 2005b) est une étude de cohorte rétrospective porte sur 407391 travailleurs ayant travaillé au moins un an dans un des 154 sites nucléaires de 15 pays, et qui avaient eu une surveillance dosimétrique individuelle, en excluant les cas où la dose par contamination interne ou irradiation par des neutrons dépassait $10 \%$ de la dose totale. La dose cumulée moyenne reçue par ces travailleurs était de 19,4 mSv; moins de $5 \%$ ayant reçu une dose cumulée de $100 \mathrm{mSv}$ ou plus. En postulant une relation linéaire sans seuil, 
l'étude montre un excès de risque relatif de cancer solide de 0,97 par sievert, I.C. $95 \%=0,14-1,97$, et estime que dans la cohorte 1 à $2 \%$ de la mortalité par cancer est due à l'irradiation reçue. L'étude ne montre pas d'excès significatif de leucémies. Nous y reviendrons.

Une controverse concerne le radon et les cancers du poumon chez l'homme, nous y reviendrons.

Les radiologues et les techniciens de radiologie qui ont commencé à travailler dans les années 1960 (ou 1970 pour la Chine), et reçu des doses de 10 à $50 \mathrm{mSv} / \mathrm{an}$ et donc une dose cumulée de plusieurs centaines de $\mathrm{mSv}$, n'ont pas de risque de cancer significativement augmenté, comme le montrent les études de cohortes importantes USA 87000 (Mohan et al., 2003, 2002; Sigurdson et al., 1997) et 117000 (Doody et al., 1998) ; Chine 17000 (Wang et al., 2002) ; Angleterre 1400 (Berrington et al., 2001). Cette absence d'excès de risque concerne également les organes particulièrement radiosensibles comme le sein, la thyroïde et le tissu hématopoïétique.

Il n'a pas été mis en évidence d'augmentation de l'ensemble des cancers, ni des cancers des organes les plus radiosensibles chez 44000 personnes appartenant au personnel navigant des compagnies aériennes (Blettner et al., 2003 ; Zeeb et al., 2003) soumis à une exposition de 1,5 à $6 \mathrm{mSv}$ par an. Seul un excès de mélanomes a été observé, explicable par une exposition plus fréquente au soleil.

\section{L'irradiation naturelle}

Les études conduites dans des régions où l'irradiation naturelle est nettement plus élevée qu'en France ne montrent pas de lien entre le niveau d'irradiation naturelle et la mortalité par cancer bien que l'on observe des stigmates biologiques de l'effet des radiations sur les lymphocytes circulants :

- province indienne du Kerala, jusqu'à 70 mSv par an (Nair et al., 1999) ;

- région chinoise du Yangijang, avec suivi comparatif depuis dix ans de 100000 habitants de zones à $6 \mathrm{mSv}, 4 \mathrm{mSv}$ et à $2 \mathrm{mSv}$ par an (Sugahara et Watanabe, 1994 ; Tao et al., 2000 ; Wang et al., 1990 ; Wei et Sugahara, 2000);

- Japon, irradiation due au radon (Mifune et al., 1992 ; Noguchi et al., 1986 ; Sobue et al., 2000).

De même il n'est pas rapporté d'augmentation du nombre de translocations chromosomiques en Chine (Hayata et al., 2004). Il s'agit dans tous les cas de très faibles débits de dose. 


\section{Les irradiations médicales}

Dans le cadre des irradiations médicales diagnostiques (débit de dose élevé), aucune des études incluant une reconstitution de l'exposition fiable, n'a montré d'augmentation du risque de leucémie après des examens radiologiques, même répétés, pour des doses cumulées inférieures à $100 \mathrm{mSv}$ (Boice et al., 1991a, 1991b ; Davis et al., 1989 ; Spengler et al., 1983). Il en est de même du risque de cancer thyroïdien radioinduit après des examens radiologiques répétés chez l'enfant ou l'adulte (Franklyn et al., 1999 ; Inskip et al., 1995). Trois études de cohorte ont montré l'augmentation du risque de cancer du sein après des examens radiodiagnostiques répétés, avec une relation dose-effet linéaire à partir de $500 \mathrm{mSv}$ et un risque relatif décroissant fortement avec l'âge au moment de l'exposition (Boice et al., 1991a, 1991b ; Doody et al., 2000 ; Hoffman et al., 1989 ; Hrubec et al., 1989 ; Miller et al., 1989; Preston et al., 2002). Aucune de ces études n'a montré d'augmentation significative du risque au dessous de $500 \mathrm{mSv}$.

En radiothérapie, les doses sont beaucoup plus élevées, administrées à fort débit, et les organes qui ne se trouvent pas dans le volume cible peuvent recevoir des doses variant entre quelques mGy et plusieurs Gy. Le risque varie fortement avec l'âge des sujets irradiés (de Vathaire et al., 2000). On a trouvé ainsi une augmentation du risque de cancer chez 160000 femmes guéries d'un cancer du col traité par radiothérapie, mais sans effet cancérogène sur les organes ayant reçu moins de $50 \mathrm{mGy}$ (Boice et al., 1998). Un excès significatif de risque relatif de cancer du sein de 2,25 (IC : 0,59-5,62) a été trouvé chez des femmes traitées dans l'enfance par radiothérapie pour hémangiome, avec des doses moyennes au sein de 1,5 Gy (Rubino et al., 2003). Une relation doseeffet purement quadratique, sans composante linéaire, a été mise en évidence dans une cohorte de 7700 femmes traitées par radiothérapie à l'Institut Gustave Roussy pour cancer du sein (Rubino et al., 2003) ; le risque, très inférieur à celui observé dans la cohorte $\mathrm{HN}$, est négligeable pour des doses inférieures à plusieurs Gy. Les données provenant de séries de malades traités par radiothérapie confirment une forte diminution du risque de cancer secondaire après irradiation fractionnée ou continue à faible débit de dose (Rubino et al., 2003).

La radiothérapie métabolique par l'iode-131 conduit à des débits de dose beaucoup plus faibles que la radiothérapie externe. L'administration d'iode131 n'augmente pas le risque de cancer thyroïdien chez l'adulte : 10000 sujets traités pour hyperthyroïdie (Holm et al., 1991) et 36800 sujets ayant eu une scintigraphie (Dickman et al., 2003). Aucun effet n'a été observé chez l'enfant, mais dans ce cas, les effectifs étudiés étaient très faibles (1900 sujets de moins 
de 20 ans et 800 de moins de 18 ans (Hahn et al., 2001)) et d'âge moyen plus élevé que les enfants de l'ex-URSS ayant développé un cancer thyroïdien à la suite de Tchernobyl.

L'irradiation médicale in utero a fait l'objet d'une étude de cohorte de grande taille dite «Étude d'Oxford» (Doll et Wakeford, 1997 ; Wakeford et Little, 2003) qui a conclu que le risque de cancer était augmenté pour des doses de l'ordre de $10 \mathrm{mSv}$. Bien que réalisée de manière rigoureuse, cette étude n'est pas exempte de faiblesses et n'est pas en accord avec d'autres données plus récentes (Shu et al., 2002 ; Naumburg et al., 2002).

- Chez les 807 enfants exposés in utero à Hiroshima et Nagasaki et suivis jusqu'en 1992, la borne supérieure de l'excès de risque relatif était de 0,6 \% pour $1 \mathrm{mGy}$ (Delongchamp et al., 1997) valeur 10 fois inférieure à celle obtenue (Bithell, 1993) dans l'étude d'Oxford. Par ailleurs, les études d'Oxford d'une part, de Monson et MacMahon (1984) d'autre part, n'ont trouvé d'augmentation du risque que pour les enfants décédés avant 10 ans alors que l'étude d'Hiroshima Nagasaki couvre une période plus longue.

- L'excès de risque trouvé dans l'étude d'Oxford est à peu près équivalent pour presque toutes les localisations de cancers (leucémies, lymphomes, neuroblastomes, ...), alors que toutes les autres études trouvent des relations dose-effet très différentes selon les tissus et organes.

- Dans le passé, les grossesses gémellaires ont eu en moyenne environ 2 fois plus d'examens radiologiques diagnostiques que les autres (UNSCEAR, 1994). Les études comparant le taux d'incidence des cancers dans les populations de jumeaux et dans la population générale évitent un biais potentiel des autres études car le fait d'avoir reçu plus d'examens n'était pas lié à une pathologie entraînant éventuellement, en elle-même, un risque ultérieur de cancer pour l'enfant à naître. À l'exception d'une seule étude cas-témoin (pour laquelle on ne peut exclure un biais d'anamnèse, les cas ayant tendance à mieux se rappeler leurs antécédents d'exposition que les témoins) (Harvey et al., 1985), ces études ne montrent pas d'excès de cancers chez les jumeaux (Rodvall et al., 1990, 1992), certaines montrant une réduction importante de l'incidence des cancers (Inksip et al., 1991 ; Mole, 1974). Il est remarquable que les études montrant un effet soient de type cas-témoins alors que les études de cohortes sont négatives. Ceci fait envisager l'existence de biais, en particulier d'anamnèse. Nous y reviendrons.

Il apparaît donc que les données sur l'effet cancérogène d'une irradiation in utero sont trop fragiles et contradictoires pour servir de base à une méthode d'évaluation du risque des faibles doses chez les enfants et les adultes. 
Au total, à l'exception de certains résultats concernant l'irradiation in utero, aucune étude épidémiologique de cohorte ou cas-témoins correctement réalisée n'a démontré un effet cancérigène des doses de rayonnements ionisants inférieures à environ $100 \mathrm{mSv}$. L'ensemble des études réalisées à ce jour concerne des populations de taille importante, dont le total est largement supérieur à celui des survivants d'Hiroshima et Nagasaki. Si certaines des sources d'information souffrent de lacunes, (comme l'absence d'estimation dosimétrique individuelle pour les radiologues), un nombre important d'études reposent sur une reconstitution dosimétrique de bonne qualité et qui dépend de moins d'hypothèses invérifiables que celle relative aux survivants d'Hiroshima et Nagasaki.

\section{Les divergences entre les rapports}

Le rapport conjoint des deux académies françaises et le rapport BEIR VII aboutissent à des conclusions différentes. Le rapport conjoint déconseille l'utilisation de la RLSS pour estimer les risques des faibles doses, alors que le rapport BEIR VII et celui de la CIPR recommandent son usage tout en reconnaissant les incertitudes qui pèsent sur elle. Comment expliquer ces divergences?

1. Sur le plan biologique, en ce qui concerne la réparation de l'ADN, le rapport BEIR indique que le nombre de lésions dans une cellule influence la qualité de la réparation, mais n'en tire aucune conclusion sur la relation dose effet, contrairement au rapport conjoint. Il admet l'hypersensibilité initiale mais en minimise l'importance. Comme le mécanisme qui la sous-tend est encore mal connu, il considère qu'on ne peut pas encore en tenir compte. Au contraire, le rapport conjoint considère qu'il constitue un argument important en faveur de l'augmentation de l'efficacité des systèmes de réparation quand ceux-ci sont stimulés (Marples et al., 2004 ; Chalmers et al., 2004).

Le rapport BEIR exprime le même scepticisme à propos des travaux de Vilenchik sur la variation des effets mutagènes par unité de dose (Vilenchik, 2000) et dit que comme les systèmes de réparation de l'ADN ne sont pas inductibles, il ne devrait pas exister de variation de leur efficacité. Le rapport conjoint souligne au contraire que l'efficacité de la réparation peut être modulée par divers facteurs, tels que l'arrêt temporaire de cycle qui donne aux cellules des délais variables en fonction de la dose pour réparer les lésions, la stimulation de divers systèmes de réparation, ou l'existence d'une irradiation antérieure (effet d'adaptation). De plus Vilenchik vient de confirmer et d'étendre ses observations (Vilenchik et Knudson, 2006). 
L'induction des systèmes de détoxication et d'anti-oxydants provoquée par une irradiation réduit le nombre de lésions avec une efficacité qui dépend de la dose. Ce fait n'est pas discuté dans les rapports BEIR.

Le rapport BEIR cite les articles de Rothkamm et Löbrich (2003) et Collis et al. (2004) mais, sans discuter le devenir des cellules lésées, il exprime des doutes sur la validité des données expérimentales; or une récente publication de Lobrich et al. (2005) confirme la validité de la technique utilisée et contrairement à ce qui a été avancé (Brenner et Sachs, 2006), ne remet pas en cause le décès des cellules lésées après une dose très faible (1,2 $\mathrm{mGy})$.

Le rapport BEIR évoque l'hypothèse d'un supralinéarité à faible dose s'appuyant sur deux phénomènes : l'effet bystander et l'instabilité génétique.

- Si l'effet bystander pouvait entraîner une cancérogenèse, ce phénomène aurait du être détecté chez les sujets ou les animaux contaminés par radionucléide émetteur de particules $\alpha$, ce qui n'est pas le cas. Pour les expositions à des rayonnements ionisants de faible TEL, l'effet bystander entraîne essentiellement la mort de cellules cibles, par apoptose ou par un mécanisme voisin qui persiste pour les cellules déficientes en p53, mais est absent chez certaines lignées cellulaires tumorales (Mothersill et Seymour, 2006a, 2006b). Globalement, les données biologiques par transfert de milieux de culture (Lyng et al., 2006a; Liu et al., 2006) ou par microirradiation sélective (Lyng et al., 2006b) montrent des effets d'apoptose à seuil et les données animales sont plus en faveur d'effets à seuil (Tanooka 2001) ou d'hormésis à faible dose (Duport, 2003) que de supralinéarité. Les études in vitro (Redpath, 2004 ; Ko et al., 2006) sont en bon accord avec l'expérimentation animale suggérant ainsi une très faible efficacité, voire un effet d'hormésis à faible dose.

- De même l'instabilité génétique radio-induite ne semble pas capable d'induire des cancers à faibles doses. Dans la majorité des études expérimentales à faible dose les conséquences les plus évidentes de l'instabilité génétique induite sont la mort cellulaire différée (Mothersill et Seymour, 1997 ; Lyng et al., 2002).

2. Sur le plan épidémiologique, le BEIR VII et le rapport conjoint considèrent qu'il n'y a pas de preuve d'un effet cancérogène pour des doses inférieures à $100 \mathrm{mSv}$. En revanche, l'article de 2003 (Brenner et al., 2003) se fonde sur la linéarité de la relation dose-effet en ce qui concerne les tumeurs solides chez les survivants d'Hiroshima-Nagasaki pour calculer l'effet cancérigène des faibles doses. Nous avons vu qu'une reconstitution dosimétrique plus précise et un recul plus long (Preston et al., 2004) ont montré que cette relation n'est pas linéaire. 
Le rapport BEIR VII et celui de la CIPR accordent beaucoup d'importance aux effets cancérogènes de l'irradiation in utero en se fondant sur des études castémoins déjà anciennes et ils admettent que les pelvimétries délivrent une dose de $10 \mathrm{mSv}$, ce qui est très discutable. Le rapport conjoint, comme beaucoup d'analyses antérieures, met en doute la validité de ces résultats en raison : (a) des incertitudes concernant la dose délivrée au cours de ces examens qui pourraient, dans certains cas, avoir été beaucoup plus grande que $10 \mathrm{mSv}$, (b) des contradictions entre les données publiées, notamment l'absence d'effet leucémogène dans des études récentes (Oppenheim et al., 1975 ; Shu et al., 2002 ; Naumburg et al., 2002), (c) des contradictions entre ces observations et celles faites après Hiroshima et Nagasaki, (d) du biais possible résultant des pathologies ayant motivé ces examens. Rien ne prouve que les troubles qui ont conduit les obstétriciens à faire pratiquer ces examens n'étaient pas associés à des facteurs susceptibles d'accroître également l'incidence de certains cancers, (e) la comparabilité des mères ayant ou n'ayant pas subi une pelvimétrie n'est pas établie. Les femmes ayant subi un examen pelvimétrique appartenaient à un niveau socioprofessionnel plus favorisé, or on sait qu'un niveau social élevé est associé à une augmentation de la fréquence de certains cancers de l'enfant, notamment des leucémies (Mezei et al., 2006).

Enfin, le rapport conjoint attache beaucoup d'importance aux études portant sur les sujets contaminés par des radionucléides émetteurs $\alpha$ que les deux autres rapports n'évoquent pas. Il a semblé, aux auteurs du rapport conjoint, impossible de discuter la radiocancérogenèse sans analyser les effets d'une irradiation avec les particules $\alpha$ puisqu'elles causent plus de dommages cellulaires que les électrons. Or pour les alpha, l'existence d'un seuil est indiscutable dans les enquêtes sur les peintres de cadran lumineux contaminés par le radium qui ne montrent aucune augmentation de l'incidence des ostéosarcomes pour des doses inférieures à quelques Gy (Rowland et al., 1983 ; Stebbings et al., 1984 ; Carnes et al., 1997 ; Thomas, 1995 ; Fry, 1998) et celles effectuées sur des malades qui avaient reçu des injections intraveineuses de thorotrast qui ne montrent aucune augmentation de la fréquence des cancers du foie pour des doses inférieures à 2 Gy (Van Kaick et al., 1991 ; Andersson et Storm, 1992 ; Travis et al., 2003, 2001 ; Nyberg et al., 2002).

Les données de l'expérimentation animale vont en général dans le même sens : Sanders a montré qu'après inhalation d'oxyde de ${ }^{239} \mathrm{Pu}$ par des rats wistar, on n'observe un excès de cancers du poumon qu'au dessus d'1 Gy au poumon (Sanders et al., 1993) ; le même résultat a été observé chez des chiens qui ont inhalé de l'oxyde de plutonium-239 ou de l'oxyde de plutonium-238 (Park, 1991, 1989). Raabe a obtenu des seuils de 0,8 à 1 Gy pour l'induction de 
cancers osseux chez des chiens exposés au radium-226 ou au strontium-90 (Raabe et Book, 1981 ; Raabe et al., 1983).

Ces données sont incompatibles avec une relation linéaire sans seuil, alors que c'est précisément pour les rayonnements alpha que ce type de relation serait le plus plausible.

\section{Discussion}

L'étude internationale du CIRC de mortalité par cancer des travailleurs de l'industrie nucléaire (Cardis et al., 2005b), parfois citée à l'encontre du rapport biacadémique, appelle plusieurs remarques.

- Le niveau moyen des expositions est très faible, nettement inférieur à la somme des expositions naturelles et médicales pendant le même temps ; il est surprenant de ne pas trouver de stratification des données pour cet important facteur de confusion. L'incertitude dosimétrique n'est pas discutée : fiabilité des dosimètres photographique au «fading », étude des conditions du recueil des données dans les périodes antérieures aux années 1960 où la culture de radioprotection était peu développée et le port des dosimètres loin d'être généralisé en situation d'exposition modérée.

- L'exploitation statistique des données est fondée sur le postulat d'une RLSS entre la dose et l'excès de risque relatif. Les mécanismes biologiques de défense contre les RI étant différents, cette approche « globale » devrait être validée en vérifiant que les pentes d'une telle relation obtenues d'une part pour seules les faibles doses $(<100 \mathrm{mSv})$ et d'autre part pour les doses plus élevées sont statistiquement compatibles, ce qui n'a pas été fait (ou du moins n'est pas rapporté). Faute de cette vérification, cette étude ne peut pas être considérée comme une preuve que la relation dose-effet cancérogène à faible dose a la même pente qu'à forte dose. L'auteur principal le reconnaît d'ailleurs : « si les doses supérieures à $200 \mathrm{mSv}$ étaient exclues de l'analyse, la conclusion générale n'en serait pas modifiée mais les résultats ne seraient plus significatifs » (Nucleonics week 7 juillet 2005). Aucune des données de base n'étant disponible, on ne peut pas tester la réalité du risque dans la gamme des faibles expositions.

- L'étude montre des écarts très importants, non expliqués, entre les risques estimés pour les six cohortes comprenant plus de 100 décès. Au Canada, le risque de cancer solide est particulièrement élevé, avec un intervalle de confiance au-dessus de celui obtenu en regroupant toutes les cohortes. La cohorte canadienne «tire»l'ensemble: les résultats ne sont plus 
significatifs si on l'exclut. Cette cohorte est vraiment singulière, montrant en particulier une forte relation dose-effet pour les maladies cardio-vasculaires (Howe et al., 2004) non identifiée, dans les autres cohortes. On peut donc suspecter un facteur de confusion lié à la dose. Il pourrait s'agir du tabagisme, mais aussi de la dosimétrie : cette cohorte concerne des sujets ayant travaillé pendant ou immédiatement après la guerre, à un moment où la dosimétrie était imprécise. Dans les cohortes concernant des sujets ayant travaillé ultérieurement, aucun excès de cancer n'est observé.

- Cette étude ne comporte aucune évaluation du tabagisme qui est pourtant un facteur de confusion potentiel majeur dans la mesure où, à travers la durée d'exposition, il peut y avoir une association entre cette exposition cumulée (en paquets $x$ années) et la dose de rayonnements ionisants. Un effet de confusion pourrait être particulièrement net pour les cancers pleuropulmonaires ou des voies aériennes supérieures. Si on exclut les cancers liés au tabac, l'excès de risque relatif de cancer solide attribué aux rayonnements ionisants généralement n'est plus significatif. On retrouve ici une difficulté rencontrée dans l'estimation des risques du radon chez les mineurs d'uranium.

- L'étude, comme d'autres, montre un «effet du travailleur sain» inhabituellement important dont l'origine mériterait une analyse approfondie et qui ne serait explicable que si les travailleurs avaient une consommation d'alcool et de tabac nettement inférieure à celle de la population générale, or rien ne le montre. L'hypothèse de linéarité retenue oblige à considérer que la relation dose-effet est monotone alors que l'effet du travailleur sain peut masquer des effets de stimulation inversement dépendant de la dose (Scott, 2006).

Une autre controverse concerne le radon et les cancers du poumon chez l'homme. Certaines études cas-témoin (Darby et al., 2006, 2005 ; Krewski et al., 2005) montrent un excès de risque relatif compris entre 0,08 et 0,16 par $100 \mathrm{~Bq} / \mathrm{m}^{3}$, pour une exposition résidentielle à un niveau de radon de $200 \mathrm{~Bq} / \mathrm{m}^{3}$, ce qui correspond à une dose équivalente aux tissus bronchiques comprise entre 25 et $75 \mathrm{mSv}$ par an ( 625 à $1,875 \mathrm{mSv}$ en 25 ans), selon les estimations des publications 65 et 66 de la CIPR.

Ces études qui regroupent plus de 10000 cancers du poumon ont une bonne puissance statistique. Toutefois, bien qu'il n'ait pas été observé dans ces études d'interaction significative entre exposition au radon et tabagisme (le risque est simplement multiplicatif), la démonstration d'un effet cancérigène du radon pour les faibles expositions nécessite à la fois la modélisation linéaire et la stratification sur le tabagisme, ce qui laisse une importante incertitude compte tenu de l'effet 
majeur du tabac. Il aurait fallu en particulier corriger du tabagisme passif chez le non-fumeur. Par ailleurs comme l'admettent les auteurs (Darby et al., 2005) un effet seuil n'est pas exclu pour les expositions inférieures à $150 \mathrm{~Bq} / \mathrm{m}^{3}$. On peut en outre rappeler ici quelques données expérimentales mettant en évidence l'extrême complexité de la relation dose-effet. Chez le rat de laboratoire très sensible à l'effet cancérogène du radon pour des expositions cumulées à fort débit, une relation complexe lie l'efficacité du radon à la dose et au débit (Monchaux et al., 1999 ; Monchaux, 2004). Aux doses cumulées les plus faibles (équivalentes à moins de $100 \mathrm{mSv}$ en dose efficace chez l'homme) seuls les forts débits (liés aux concentrations de plusieurs milliers de $\mathrm{Bq} / \mathrm{m}^{3}$ de radon dans l'air inhalé) sont associés au cancer. Aux doses cumulées moyennes et fortes l'efficacité cancérogène du radon croît en fonction inverse du débit, comme cela a été décrit pour les mineurs d'uranium fortement exposés. Il devrait donc être pris en compte en épidémiologie des paramètres de débit que le simple enregistrement passif des produits de filiation du radon en un point de l'habitat ne peut évidemment modéliser.

Il demeure que l'exposition au radon à $200 \mathrm{~Bq} / \mathrm{m}^{3}$ contribue à une exposition tissulaire cumulée de plusieurs centaines de mSv en dose équivalente. Ce n'est pas à proprement parler une faible dose. On peut donc se préoccuper légitimement d'en prévenir les conséquences, d'autant que les interactions de signalisation cellulaire par effet bystander entre les agressions cumulées au tabac et au radon peuvent créer les conditions d'un débordement des défenses contre le stress génotoxique (Mothersill et Seymour, 2001). Néanmoins, même si on retient l'hypothèse de linéarité, l'impact sanitaire d'une mesure de prévention visant à réduire l'exposition domestique au-dessous de $200 \mathrm{~Bq} / \mathrm{m}^{3}$ serait décevant (Samet et Speizer, 1993) du simple fait de la répartition très majoritaire du risque pour les expositions domestiques dont $91 \%$, sous réserve d'un biais d'échantillonnage des habitations étudiées, sont situées au-dessous de ce niveau (Gambard et al., 2000). Un tout autre résultat serait acquis si on évitait l'exposition à la fumée de cigarette, cette mesure affecterait l'ensemble des expositions domestiques au radon et ferait chuter le nombre de cancers du poumon, éventuellement imputables au radon, d'un incontestable facteur 10 .

Au total, si ces données méritent attention, elles n'emportent pas la conviction et on ne saurait se fonder sur elles pour estimer le risque des faibles doses.

Pour des raisons de puissance statistique, la démarche actuellement adoptée dans la plupart des études épidémiologiques consiste à estimer les risques en fusionnant des données obtenues pour des gammes de doses très étendues, par exemple de quelques $\mathrm{mSv}$ à $500 \mathrm{mSv}$. Cette démarche sous entend implicitement que les mécanismes de cancérogenèse sont les mêmes (ou du moins similaires) 
pour les faibles doses et pour des doses nettement plus élevées. De plus, comme l'a montré Breckow (2006), on se trouve souvent face à une erreur méthodologique « circulaire» puisque certaines études (e.g. Brenner et al., 2003; Cardis et al., 2005a, 2005b ; Darby et al., 2005) postulent la validité d'un modèle fondé sur une relation linéaire sans seuil quelle que soit la dose pour justifier le regroupement des faibles et fortes doses. Ce regroupement conduit à un risque significatif, ce qui « démontre » l'effet des faibles doses.

Mais si on n'utilise pas ce postulat, qui ne va pas de soi puisque les mécanismes ne sont pas les mêmes selon la dose, et qu'on limite l'étude aux sujets ayant reçu moins de $100 \mathrm{mSv}$ on ne trouve pas d'effet cancérogène significatif. Un premier travail a été entrepris dans le cadre du rapport des académies : la synthèse de toutes les études de cohorte pour lesquelles il a été possible d'obtenir, dans les publications ou auprès des auteurs, des coefficients de risque fondés sur les seules doses inférieures à $100 \mathrm{mSv}$ chez l'adulte. Sur un total de plus de 415000 sujets suivis pendant 17 ans en moyenne, cette première synthèse ne montre pas d'excès de risque relatif significatif (ERR), ni pour les tumeurs solides (ERR $=-0,012$ IC $95 \%=[-0,041 ;+0,017])$, ni pour les leucémies $($ ERR $=0,032$ IC $95 \%=$ $[-0,11 ; 0,19])$.

Cette approche doit être poursuivie, en analysant sans a priori l'ensemble des données disponibles concernant les faibles expositions.

\section{Conclusion}

La relation linéaire sans seuil ne pourrait être considérée comme scientifiquement établie que si on démontrait la constance de la probabilité de réparation fautive par unité de dose, ainsi que la constance de la probabilité pour une lésion de l'ADN de donner naissance à un cancer quel que soit le nombre d'autres lésions de l'ADN dans la même cellule et les cellules voisines. En l'absence de ces démonstrations, l'usage de la RLSS, pour estimer l'effet nocif des doses de l'ordre de quelques mGy, reste une simple hypothèse, contredite par de nombreuses données biologiques et épidémiologiques. Cependant, l'absence de validité de la RLSS ne signifie pas absence d'effet cancérigène pour des faibles doses et les données actuelles ne permettent pas d'exclure un effet cancérigène qui serait beaucoup plus faible par unité de dose que ce que prédit la RLSS. De même, on ne peut pas exclure l'existence d'un seuil ou même d'un effet d'hormésis.

Une surestimation des risques des faibles doses paraissait jusqu'à ces dernières années sans inconvénient, ne conduisant au pire qu'à une surprotection superflue. La directive 97/43 de la Commission européenne sur les examens radiologiques a changé la donne puisque avant d'effectuer une procédure médicale utilisant les 
rayonnements ionisants, elle impose de mettre en balance le bénéfice qu'il peut apporter (dépistage, diagnostic ou traitement) et les risques qu'il induit. Dès lors, une surestimation du risque pourrait faire renoncer à des examens utiles (par exemple les mammographies de dépistage) et avoir un effet négatif en santé publique. Les évaluations qui ont été faites (Berrington de Gonzales et Darby, 2004) du nombre de cancers provoqués par des examens radiologiques ont quantifié l'ampleur de ce risque en utilisant une relation dose-risque linéaire sans seuil. Si cette méthode était pertinente, les examens radiologiques (Donadieu et al., 2006) seraient une des causes majeures de cancer en France (plus de 4500 par an). Ceci est très peu plausible.

Ces rappels montrent que s'il est nuisible de sous-estimer les risques des radiations ionisantes, il est non moins dangereux de les surestimer (Jaworowski, 2006). Dans certains cas, les craintes suscitées par la radioactivité peuvent causer plus de victimes que la radioactivité. On peut citer par exemple la panique après Three Mile Island ou, après Tchernobyl, la centaine de milliers de personnes évacuées de certains territoires qui ne le justifiaient pas et les nombreuses interruptions volontaires de grossesse sans motif valable (Castronovo, 1999). Sur ce point aussi la RLSS mérite d'être reconsidérée.

La RLSS est d'une simplicité commode en radioprotection (où d'ailleurs elle n'intervient pas explicitement), mais l'estimation des effets des faibles doses, par exemple dans une analyse coût-bénéfice ou pour prévoir les conséquences de faibles expositions portant sur des populations importantes, nécessite d'abandonner ce modèle simpliste et d'élaborer des outils qui bénéficient des progrès de nos connaissances.

L'estimation des risques des faibles doses de RI ne peut plus reposer sur des études épidémiologiques qui, pour des raisons de puissance statistique, amalgament des doses conduisant à des réponses cellulaires, tissulaires et immunologiques radicalement différentes. Il est au contraire nécessaire de conduire des études spécifiquement limitées aux faibles doses ou sans a priori quant à la forme de la relation dose-effet, et disposant d'une évaluation précise de facteurs de confusion potentiels dont l'effet cancérogène est beaucoup plus puissant que celui que l'on cherche à quantifier. Il est possible que la mise en commun des données des nombreuses études épidémiologiques déjà conduites permette d'avancer significativement dans cette voie. Il est urgent de mener à bien une telle méta analyse. 


\section{RÉFÉRENCES}

Amundson S.A., Lee R.A., Koch-Paiz C.A., Bittner M.L., Meltzer P., Trent J.M., Fornace A.J. Jr (2003) Differential responses of stress genes to low dose-rate gamma irradiation, Mol. Cancer Res. 1, 445-452.

Andersson M., Storm H.H. (1992) Cancer incidence among Danish thorotrast-exposed patiens, J. Natl. Cancer Inst. 84, 1318-1325.

Averbeck D. (2000) Mecanismes de réparation et mutagénèse radioinduite chez les eucaryotes supérieurs, Cancer Radiother. 4, 1-20.

Averbeck D. (2007) New biological data in relation with low dose risk, DOE, in press.

Averbeck D., Testard L., Boucher D. (2006) Changing views on ionizing radiation-induced cellular effects, Int. J. Low Rad. 3, 117-134.

Bakkenist C.J., Kastan M.B. (2004) Initiating cellular stress responses, Cell 118, 9-17.

Barcellos-Hoff M.H. (2005) Integrative Radiation Carcinogenesis: interactions between cell and tissue responses to DNA damage, Sem. Cancer Biol. 15, 138-148.

Bartkova J., Rezaei N., Liontos M. et al. (2006) Oncogene-induced senescence is part of the tumorigenesis barrier imposed by DNA damage checkpoints, Nature 444, 633-637.

Beachy P.A., Karhadhar S.S., Berman D. (2004) Tissue repair and stem cell renewal in carcinogenesis, Nature 432, 324-331.

BEIR VII (2005) National Research Council of the National Academies of USA, Health risk from exposure to low levels of ionizing radiation. Pre-publication version, July 2005.

Belyakov O.V., Folkard M., Mothersill C., Prise K.M., Michael B.D. (2006) Bystander induced differentiation: a major response to targeted irradiation of a urothelial explant model, Mutat. Res. 597, 43-49.

Berrington A., Darby S.C., Weiss H.A., Doll R. (2001) 100 years of observation on British Radiologists: mortality from cancer and other causes 1987-1997, Br. J. Radiology 74, 507-519.

Berrington de Gonzalez A., Darby S. (2004) Risk of cancer from diagnostic X-rays: estimates for the UK and 14 other countries, Lancet 363, 345-351.

Bhowmick N.A., Chytil A., Plieth D., Gorska A.E., Dumont N., Shappell S., Washington M.K., Neilson E.G., Moses H.L. (2004) TGF-beta signaling in fibroblasts modulates the oncogenic potential of adjacent epithelia, Science 303, 775-777.

Bishay K., Ory K., Olivier M.F., Lebeau J., Levalois C., Chevillard S. (2001) DNA damage-related RNA expression to assess individual sensitivity to ionizing radiation, Carcinogenesis 22, 11791183.

Bithell J.F. (1993) Statistical issues in assessing the evidence associating obstetric irradiation and childhood malignancy, E. Lengfelder, H. Wendhausen (Eds). Neue Bewertung des Strahlenriskos, Niedrigdosis Strahlung und Gesundheit, Munich, pp. 53-60.

Blettner M., Zeeb H., Auviven A. et al. (2003) Mortality from cancer and other causes among male airline cockpit in Europe, Int. J. Cancer 106, 946-952.

Boice J.D., Preston D., Davis F.G., Monson R.R. (1991a) Frequent chest X-ray fluoroscopy and breast cancer incidence among tuberculosis patients in Massachusetts, Radiat. Res. 125, 214-222.

Boice J.D.J., Morin M.M., Glass A.G. et al. (1991b) Diagnostic X-ray procedures and risk of leukemia, lymphoma, and multiple myeloma, JAMA 265, 1290-1294.

Boice J.D.J., Engholm G., Kleinerman R.A. et al. (1998) Radiation dose and second cancer risk in patients treated for cancer of the cervix, Radiat. Res. 116, 3-55.

Boucher D., Hindo J., Averbeck D. (2004) Increased repair of gamma-induced DNA double-strand breaks at lower dose-rate in CHO cells, Can. J. Physiol. Pharmacol. 82, 125-132.

Brash D.E. (1997) Sunlight and the onset of skin cancers, Trend. Genet. 13, 410-414. 
Bravard A., Luccioni C., Moustacchi E., Rigaud O. (1999) Contribution of antioxydant enzymes in the adaptative response to ionizing radiation of human lymphoblasts, Int. J. Radiat. Biol. 75, 639645 .

Breckow J. (2006) Linear-no-threshold is a radiation-protection standard rather than a mechanistic effect model, Radiat. Environ. Biophys. 44, 257-260.

Brenner D.J., Doll R., Goodhead D.T., Hall E.J., Land C.E., Little J.B., Lubin J.H., Preston D.L., Preston R.J., Puskin J.S., Ron E., Sachs R.K., Samet J.M., Setlow R.B., Zaider M. (2003) Cancer risk attributable to low doses of ionizing radiation: Assessing what we really know, Proc. Natl. Acad. Sci. USA 100, 13761-13766.

Brenner D.J., Sachs R.K. (2006) Estimating radiation-induced cancer risks at very low doses: rationale for using a linear no-threshold approach, Radiat. Environ. Biophys. 44, 253-256.

Burns F.J., Albert R.E. (1986) "Dose-response for radiation-induced cancer in rat skin", In Radiation carcinogenesis and DNA alterations, F.J. Burns, A.C. Upton, G. Silini (Eds). Plenum Press, Lifes Sciences, pp. 51-70.

Cardis E., Gilbert E.S., Carpenter L. et al. (1995) Effects of low dose rates of external ionizing radiation: cancer mortality among nuclear industry workers in three countries, Radiat. Res. 142, 117-132.

Cardis E., Kesminienne A., Ivanov V. et al. (2005a) Risk of thyroid cancer after exposure to ${ }^{131} \mathrm{I}$ in childhood, J. Nat. Cancer Inst. 97, 724-732.

Cardis E., Vrijheid M., Blettner M. et al. (2005b) Risk of cancer after low doses of ionising radiation : retrospective cohort study in 15 countries, Brit. Med. J. 333, 77-83.

Cardis E., Howe G., Ron E., Bebeshko V.G., Bogdanova T., Bouville A. et al. (2006) Cancer consequences of the Chernobyl Accidet: 20 Years After, J. Radiol. Prot. 26, 125-137.

Carnes B.A., Groer P.G., Kotec T.J. (1997) Radium dial workers: Issues concerning dose response and modeling, Radiat. Res. 147, 707-714.

Castronovo F. (1999) Teratogen update: Radiation and Chernobyl, Teratology 60, 100-106.

Chalmers A., Johnston P., Woodcock M., Joiner M., Marples B. (2004) PARP-1, PARP-2, and the cellular response to low doses of ionizing radiation, Int. J. Radiat. Oncol. Biol. Phys. 58, 410419.

Collis S.J., Schwaninger J.M., Ntambi A.J., Keller T.W., Nelson W.G., Dillehay L.E., Deweese T.L. (2004) Evasion of early cellular response mechanisms following low level radiation induced DNA damage, J. Biol. Chem. 279, 49624-49632.

Darby S., Hill D., Auvinene A., Barros-Dios J.M. et al. (2005) Radon in homes and risk of lung cancer: collaborative analysis of individual data from 13 European case-control studies, Brit. Med. J. 330, 223-227.

Darby S., Hill D., Deo H., Auvinen A. et al. (2006) Residential radon and lung cancer-detailed results of a collaborative analysis of individual data on 7148 persons with lung cancer and 14,208 persons without lung cancer from 13 epidemiologic studies in Europe, Scand. J. Work Environ. Health 32 (Suppl 1), 1-83.

Davis F.G., Boice J.D.J., Hrubec Z., Monson R.R. (1989) Cancer mortality in a radiation-exposed cohort of Massachusetts tuberculosis patients, Cancer Res. 49, 6130-6136.

De Toledo S.M., Asaad N., Venkatachalam P., Li L., Howell R.W., Spitz D.R., Azzam E.I. (2006) Adaptive responses to low-dose/low-dose-rate gamma rays in normal human fibroblasts: the role of growth architecture and oxidative metabolism, Radiat. Res. 166, 849-857.

de Vathaire F., Hardiman C., Shamsalidin A. et al. (2000) Thyroid carcinoma following irradiation for a first cancer during childhood, Arch. Inter. Med. 159, 2713-2719. 
Delongchamp R.R., Mabushi K., Yasuhiko Y. et al. (1997) Cancer mortality among atomic bomb survivors exposed in utero or as young chidren, Radiat. Res. 147, 385-395.

Dickman P.W., Holm L.E., Lundell G.R., Boice J.D., Hall P. (2003) Thyroid cancer risk after thyroid examination with ${ }^{131} \mathrm{I}$ : a population based cohort study in Sweden, Int. J. Cancer 106, 580-587.

Dikomey E., Brammer I. (2000) Relationship between cellular radiosensitivity and non-repaired double-strand breaks studied for different growth states, dose rates and plating conditions in a normal fibroblast line, Int. J. Radiat. Biol. 76, 773-781.

Doll R., Wakeford R. (1997) Risk of childhood cancer from fetal irradiation, Br. J. Radiol. 70, 130-139.

Donadieu J., Scanff P., Pirard P., Aubert B. (2006) Exposition médicale aux rayonnements ionisants à vise diagnostique de la population française : état des lieux fin 2002 en vue de la mise en place d'un système de surveillance, $B E H$ 15-16, 102-106.

Doody M.M., Mandel J.S., Lubin J.H., Boice J.D. (1998) Mortality among USA radiologic technologists 1926-1990, Cancer Causes Control 9, 67-75.

Doody M.M., Lonstein J.E., Stovall M., Hacker D.G., Luckyanov N., Land C.E. (2000) U.S. Scoliosis Cohort Study Collaborators. Breast cancer mortality following diagnostic X-rays: Findings from the U.S. Scoliosis Cohort Study, Spine 25, 2052-2063.

Duport P. (2003) A database of cancer induction by low dose radiation in mammals: overview and initial observations, Int. J. Low Radiation 1, 120-131.

Euvrard S., Kanitakis J., Claudis D. (2003) Skin cancers after organ transplantation, N. Engl. J. Med. 348, 1681-1691.

Fernet M., Ponette V., Deniaud-Alexandre E., Menissier-De Murcia J., De Murcia G., Giocanti N., Megnin-Chanet F., Favaudon V. (2000) Poly (ADP-Ribose) polymerase, a major determinant of early cell response X ionising radiation, Int. J. Rad. Oncol. Biol. Phys. 76, 73-84.

Franco N., Lamartine J., Frouin V. et al. (2005) Low-Dose Exposure to $\gamma$ rays induces specific gene regulations in normal human keratinocytes, Radiat. Res. 163, 623-635.

Franklyn J.A., Maisonneuve L., Sheppard M., Betteridge T., Boyle P. (1999) Cancer incidence and mortality after radioiodine treatment for hyperthyroidism: a population based study, Lancet 353, 2111-2115.

Fry S.A. (1998) Studies of US radium dial workers: An epidemiological classic, Radiat. Res. 150, S21S29.

Gambard J.P., Mitton N., Pirard P. (2000) Campagne nationale de mesure de l'exposition domestique au radon IPSN-DGS Bilan et représentation cartographique des mesures au $1^{\mathrm{er}}$ janvier 2000, www.ipsn.fr.

Hahn K., Schnell-Inderst P., Grosche B., Holm L.E. (2001) Thyroid cancer after diagnostic administration of iodine-131 in childhood, Radiat. Res. 156, 61-70.

Harvey E.B., Boice J.D., Honeyman M., Flannery J.T. (1985) Prenatal X-ray exposure and childhood cancer in twins, N. Engl. J. Med. 312, 541-545.

Hayata J., Wang C., Zhang W. et al. (2004). Effect of hight level natural radiation on chromosomes of residents in southern china, Cytogenet. Genome Res. 104, 237-239.

Hoffman D.A., Bronstein J.E., Morin M.M. (1989) Breast cancer in women with scoliosis exposed to multiple diagnosis X-rays, J. Natl. Cancer Inst. 81, 1307-1312.

Holm L.E., Hall P., Wiklund K. et al. (1991) Cancer risk after iodine-131 therapy for hyperthyroidism, J. Natl. Cancer Inst. 83, 1072-1077.

Howe G.R., Zablotska L.B., Fix J.J., Egel J., Buchanan J. (2004) Analysis of the mortality experience amongst U.S. nuclear power industry workers after chronic low-dose exposure to ionizing radiation, Radiat. Res. Nov. 162(5), 517-26.

Hrubec Z., Boice J.D., Monson R.R., Rosenstein M. (1989) Breast Cancer after multiple chest fluoroscopies: second follow-up of Massachusetts Women with Tuberculosis, Cancer Res. 49 229-234. 
ICRP Publication 99 (2005) Low-dose Extrapolation of Radiation-related cancer Risk, Ann. ICRP 35(4).

Inksip P.D., Harvey E.B., Boice J.D. et al. (1991) Incidence of cancer in twins, Cancer Causes Control 2, 315-324.

Inskip P.D., Ekbom A., Galanti M.R., Grimelius L., Boice J.D.J. (1995) Medical diagnostic X rays and thyroid cancer, J. Natl. Cancer Inst. 87, 1613-1621.

Ivanov V., Ilyin L., Gorski A., Tukov A., Naumenko R. (2004) Radiation and epidemiological analysis for solid cancer incidence among nuclear workers who participated in recovery operations following the accident at the Chernobyl, J. Radiat. Res. (Tokyo) 45, 41-44.

Jaworowski Z. (2006) The real Chernobyl folly, 21st century, Spring, 59-72.

Kamiya K., Yasukawa-Barnes J., Mitchen J., Gould M., Clifton K. (1995) Evidence that carcinogenesis involves an imbalance between epigenetic high frequency initiation and suppression of promotion, PNAS 92, 1332-1336.

Katayama H., Matsuura M., Endo S., Hoshi M., Ohtaki M., Hayakawa N. (2002) Reassessment of the cancer mortality risk among Hiroshima atomic-bomb survivors using a new dosimetry system, ABS2000D, compared with ABS93D, J. Radiat. Res. (Tokyo) 43, 53-64.

Ko M., Lao X.Y., Kapadia R., Elmore E., Redpath J.L. (2006) Neoplastic transformation in vitro by low doses of ionizing radiation: role of adaptive response and bystander effects, Mutat. Res. 597, 11-17.

Krewski D., Lubin J.H., Zielinski J.M., Alavanja M., Catalan V.S., Field R.W., Klotz J.B., Letourneau E.G, Lynch C.F., Lyon J.I., Sandler D.P., Schoenberg J.B., Steck D.J., Stolwijk J.A., Weinberg C., Wilcox H.B. (2005) Residential radon and risk of lung cancer: a combined analysis of 7 North American case-control studies, Epidemiology 16, 137-145.

Little M.P., Muirhead C.R. (1996) Evidence for curvilinearity in the cancer incidence dose-response in the Japanese atomic bomb survivors, Int. J. Radiat. Biol. 70, 83-94.

Little M.P., Muirhead C.R. (2000) Derivation of low dose extrapolation factors from analysis of the curvature in the cancer incidence dose response in Japanese atomic bomb survivors, Int. J. Radiat. Biol. 76, 939-953.

Liu Z., Mothersill C.E., McNeill F.E., Lyng F.M., Byun S.H., Seymour C.B., Prestwich W.V. (2006) A dose threshold for a medium transfer bystander effect for a human skin cell line, Radiat. Res. 166, 19-23.

Löbrich M., Rief N., Kuhne M., Fleckenstein J., Rube C., Uder M. (2005) In vivo formation and repair of DNA double-strand breaks after computed tomography examinations, Proc. Natl. Acad. Sci. USA 102, 8984-8989.

Loucas B.D., Eberle R., Bailey S.M. Cornforth M.N. (2004) Influence of dose rate on the induction of simple and complex chromosome exchanges by gamma rays, Radiat. Res. 162, 339-349.

Lyng F.M., Seymour C.B., Mothersill C. (2002) Initiation of apoptosis in cells exposed to medium from the progeny of irradiated cells: a possible mechanism for bystander-induced genomic instability? Radiat. Res. 57, 365-370.

Lyng F.M., Maguire P., McClean B., Seymour C., Mothersill C. (2006a) The involvement of calcium and MAP kinase signaling pathways in the production of radiation-induced bystander effects, Radiat. Res. 165, 400-409.

Lyng F.M., Maguire P., Kilmurray N., Mothersill C., Shao C., Folkard M., Prise K.M. (2006b) Apoptosis is initiated in human keratinocytes exposed to signalling factors from microbeam irradiated cells, Int. J. Radiat. Biol. 82, 393-399.

Marples B., Wouters B.G., Collis S.J., Chalmers A.J., Joiner M.C. (2004) Low-dose hyperradiosensitivity: a consequence of ineffective cell cycle arrest of radiation-damaged G2-phase cells, Radiat. Res. 161, 247-255. 
Meeting report (2006) Low-Dose Radiation Risk Assessment Report, International Workshop on Low Dose Radiation Effects, Columbia University Medical Center, New York, April 3-4, 2006, Rad. Res. 166, 561-565.

Menard C., Johann D., Lowenthal M. et al. (2006) Discovering clinical biomarkers of ionizing radiation exposure with serum proteomic analysis, Cancer Res. 66, 1844-1850.

Mercier G., Berthault N., Mary J., Peyre J., Antoniadis A., Comet J.P., Cornuejols A., Froidevaux C., Dutreix M. (2004) Biological detection of low radiation doses by combining results of two microarray analysis methods, Nucleic Acids Res. 32(1), e12.

Mezei G., Borugian M.J., Spinelli J.J., Wilkins R., Abanto Z., McBride M.L. (2006) Socioeconomic status and childhood solid tumor and lymphoma incidence in Canada, Am. J. Epidemiol. 164, 170-175.

Mifune M., Sobue T., Arimoto H., Komoto Y., Kondo S., Tanooka H. (1992) Cancer mortality survey in a spa area (Misasa, Japan) with a high radon background, Jpn J. Cancer Res. 83, 1-5.

Miller A.B., Howe G.R., Sherman G.J. et al. (1989) Mortality from breast cancer after irradiation during fluoroscopic examinations in patients being treated for tuberculosis, N. Engl. J. Med. 321, 1285-1289.

Miller R.C., Randers-Pehrson G., Geand C.R., Hall E., Brenner D.J. (1999) The oncogenic transforming potentiel of the passage of single alpha particles through mammalian cell nuclei, Proc. Natl. Acad. Sci. USA 96, 19-22.

Mohan A.K., Hauptmann M., Linet M.S. et al. (2002) Breast cancer mortality among female radiologic technologists in the United States, J. Natl. Cancer Inst. 94, 943-948.

Mohan A.K., Hauptmann M., Freedman D.M. et al. (2003) Cancer and other causes of mortality among radiologic technologists in the United States, Int. J. Cancer 103, 259-67.

Mole R.H. (1974) Antenatal irradiation and childhood cancer: causation or coincidence, Br. J. Cancer 30, 199-208.

Monchaux G. (2004). Risk of fatal versus incidental lung cancer in radon exposed rats: a reanalysis of French date, Archv. Oncol. 12, 7-12.

Monchaux G., Morlier J.P., Altmeyer S, Debroche M., Morin M. (1999) Influences of exposure rate on lung cancer induction in rats exposed to radon progeny, Radiat. Res. 152, S137-S140.

Monson R.R., MacMahon B. (1984) "Prenatal X-ray exposure and cancer in children”, In Radiation carcinogenesis: Epidemiology and biological significance, J.D. Boice, J.F. Fraumeni (Eds). Raven Press, New York, pp. 97-105.

Mothersill C., Seymour C. (1997) Lethal mutations and genomic instability, Int. J. Radiat. Biol. 71, 751-758.

Mothersill C., Seymour C. (2001) Radiation-induced bystander effects: past history and future directions, Radiat. Res. 155, 759-67.

Mothersill C., Seymour C. (2006a) Radiation-induced bystander and other non-targeted effects: novel intervention points in cancer therapy? Curr. Cancer. Drug. Targets 6, 447-454.

Mothersill C., Seymour C.B. (2006b) Radiation-induced bystander effects and the DNA paradigm: an "out of field" perspective, Mutat. Res. 11, 5-10.

Mueller M.M., Fusening N.E. (2004) Friends or foes. Bipolar effects of the tumour stroma in cancer, Nature Rev. 4, 839-849.

Nair M.K., Nambi K.S., Amma N.S. et al. (1999) Population study in the high natural background radiation area in Kerala, Ind. Radiat. Res. 152, S145-S148.

Naumburg E., Belloco R., Cnattingius S. et al. (2002) Intrauterine exposure to diagnostic of X rays and risk of childhood leukemia subtypes, Radiat. Res. 156, 718-723.

Noguchi K., Shimizu M., Anzai Z. (1986) Correlation between natural radiation exposure and cancer mortality in Japan (I), J. Radiat. Res. 27, 191-212. 
Nyberg U., Nilsson B., Travis L.B., Holm L.E., Hall P. (2002) Cancer incidence among Swedish patients exposed to radioactive thorotrast: a forty-year follow-up survey, Radiat. Res. 157, 419425.

Oppenheim B.E., Griem M.L., Meier P. (1975) The effects of diagnostic X-ray exposure on the human fetus: an examination of the evidence, Radiology 114, 529-534.

Park J.F. (1990) Inhaled plutonium oxide in dog, In "Pacific Northwest laboratory Report for 1989 to the DOE Office of Energy Research Part I: Biomedical Sciences”, Springfield, VA: National Technical Information Service, pp. 11-28, 101-107.

Park J.F. (1992) Inhaled plutonium oxide in dog, In "Pacific Northwest laboratory Report for 1991 to the DOE Office of Energy Research Part I: Biomedical Sciences”, Springfield, VA: National Technical Information Service.

Ponette V., Le Pechoux C., Deniaud-Alexandre E., Fernet M., Giocanti N., Tourbez H., Favaudon V. (2000) Hyperfast early cell response to ionising radiation, Int. J. Rad. Oncol. Biol. 72, 12331243.

Portess D.I., Bauer G., Hill M.A., O’Neill P. (2007) Low-dose irradiation of nontransformed cells stimulates the selective removal of precancerous cells via intercellular induction of apoptosis, Cancer Res. 67, 1246-1253.

Preston D.L., Mattsson A., Holmberg E., Shore R., Hildreth N.G., Boice J.D. (2002) Radiation effects on breast cancer risk: a pooled analysis of eight cohorts, Radiat. Res. 158, 220-235.

Preston D.L., Pierce D.A., Shimizu Y. et al. (2004) Effect of recent changes in atomic bomb survivor dosimetry on cancer mortality risk estimates, Radiat. Res. 162, 377-389.

Raabe O.G., Book S.A. (1981) Dose-response relationship for bone tumors in beagle exposed to ${ }^{226} \mathrm{Ra}$ and ${ }^{90} \mathrm{Sr}$, Health Phys. 40, 863-880.

Raabe O.G., Book S.A., Parks N.J. (1983) Lifetime bone cancer response relationships in beagles and people from skeletal burdens of ${ }^{226} \mathrm{Ra}$ and ${ }^{90} \mathrm{Sr}$, Health Phys. 44(Suppl 1), 33-48.

Radisky D.C., Bissell M.J. (2004) Cancer. Respect thy neighbor! Science 303, 774-775.

Redpath J.L. (2004) Radiation induced neoplastic transformation in vitro: evident for a protective effect at low doses of low LET, Rad. Cancer Metast. Rev. 23, 333-339.

Rigaud O., Moustacchi E. (1996) Radioadaptation for gene mutation and the possible molecular mechanisms of the adaptive response, Mutat. Res. 358, 127-134.

Rodvall Y., Pershagen G., Hrubec Z., Ahlbom A., Pedersen N.L., Boice J.D. (1990) Prenatal X-ray exposure and childhood cancer in Swedish twins, Int. J. Cancer 46, 362-365.

Rodvall Y., Hrubec Z., Pershagen G. et al. (1992) Childhood cancer among Swedish twins, Cancer Causes Control 3, 527-532.

Roos W.P., Kaina B. (2006) DNA damage-induced cell death by apoptosis, Trends Mol. Med.12, 440450 .

Rothkamm K., Löbrich M. (2003) Evidence for a lack of DNA double-strand break repair in human cells exposed to very low X-ray doses, Proc. Natl. Acad. Sci. USA 100, 5057-5062.

Rowland R.E., Stehney A.F., Lucas H.F. (1983) Dose-reponse relationships for radium-induced bone sarcomas, Health Phys. 44(Suppl. 1), 15-31.

Rubino C., de Vathaire F., Shamsaldin A., Labbe M., Le M.G. (2003) Radiation dose, chemotherapy, hormonal treatment and risk of second cancer after breast cancer treatment, Br. J. Cancer $\mathbf{8 9}$, 840-846.

Samet J.M., Speizer F.E. (1993) Assessment of health effects in epidemiologic studies of air pollution, Environ. Health Persp. 101(Suppl 4), 149-154.

Sanders C.L., Lauhala K.E., McDonald K.E. (1993) Lifespan studies in rats exposed to 239PuO2. III. Survival and lung tumors, Int. J. Radiat. Biol. 64, 417-430. 
Scott B. (2006) Risk of thyroid cancer after exposure to (131)I in childhood, Response Cardis E., Kesminienne A., J. Nat. Cancer Inst. 98, 561.

Shilnikova N.S., Preston D.L., Ron E. et al. (2003) Cancer mortality risk among workers at the Mayak nuclear complex, Radiat. Res. 159, 787-798.

Shu X.O., Potter J.D., Linet M.S., Severson R.K., Han D., Kersey J.H., Neglia J.P., Trigg M.E., Robison L.L. (2002) Diagnostic X-rays and ultrasound exposure and risk of childhood acute lymphoblastic leukemia by immunophenotype, Cancer Epidemiol. Biomarkers Prev. 11, 177-185.

Sigurdson A.J., Doody M.M., Rao R.S. et al. (2003) Cancer incidence in the US radiologic technologists health study, 1983-1998, Cancer 97, 3080-3089.

Sobue T., Lee V.S., Ye W., Tanooka H., Mifune M., Suyama A., Koga T., Morishima H., Kondo S. (2000) Residential radon exposure and lung cancer risk in Misasa, Japan: a case-control study, J. Radiat. Res. (Tokyo) 41, 81-92.

Spengler R.F., Cook D.H., Clarke E.A., Olley P.M., Newman A.M. (1983) Cancer mortality following cardiac catheterization: a preliminary follow-up study on 4,891 irradiated children, Pediatrics 71, 235-239.

Stebbings J.H., Lucas H.F., Stehney A.F. (1984) Mortality from cancers of major sites in female radium dial workers, Am. J. Ind. Med. 5, 435-459.

Sugahara T., Watanabe M. (1994) Epigenetic nature of radiation cancinogenesis at low doses, Int. J. Occup. Med. Toxicol. 3, 129-136.

Tanooka H. (2001) Threshold dose-response in radiation carcinogenesis: an approach from chronic beta-irradiation experiments and a review of non tumour doses, Int. J. Radiat. Biol. 77, 541-551.

Tao Z., Zha Y., Akiba S., Sun Q. et al. (2000) Cancer mortality in the high background radiation areas of Yangjiang, China during the period between 1979 and 1995, J. Radiat. Res. (Tokyo) 41, 3141.

Thomas R.G. (1995) "Tumorigenesis in the US radium luminizers: how unsafe was this occupation?", In Health Effects of Internally Deposited Radionuclides: Emphasis on Radium and Thorium, G. van Kaick, A. Karaoglou, A.M. Kellerer (Eds). World Scientific, London, Singapore, pp. 145-148.

Travis L.B., Land C.E., Andersson M., Nyberg U. (2001) Mortality after cerebral angiography with or without radioactive Thorotrast: an international cohort of 3, 143 two-year survivors, Radiat. Res. 156, 136-150.

Travis L.B., Hauptmann M., Gaul L.K. et al. (2003) Site-specific cancer incidence and mortality after cerebral angiography with radioactive thorotrast, Radiat. Res. 160, 691-706.

Tubiana M (2003) The carcinogenic effect of low doses: the validity of the linear nothreshold relationship, Int. J. Low Rad. 1, 1-31.

Tubiana M., Aurengo A., Averbeck D., Bonnin A., Le Guen B., Masse R., Monier R., Valleron A.J., de Vathaire F. (2005) Académie Nationale de Médecine, Institut de France, Académie des Sciences, Rapport Conjoint n ${ }^{\circ} 2$, Relation dose-effet et estimation des risques cancérogènes des faibles doses des rayonnements ionisants (www.academiemedecine.fr/actualites/rapports.asp). Édition Nucleon, Paris, ISBN 2-84332-018-6, pp. 1-168.

Tubiana M., Aurengo A., Averbeck D., Masse R. (2006a) Recent reports on the effect of low doses of ionizing radiation and its dose-effect relationship, Radiat. Environ. Biophys. 44, 245-251.

Tubiana M., Aurengo A., Averbeck D., Masse R. (2006b) The debate on the use of LNT for assessing the effects of low doses, J. Radiol. Prot. 26, 317-324.

UNSCEAR (1994) United Nations Scientific Committee on the Effects of Atomic Radiation, Sources, effects and risks of ionising radiation, Report to the General Assembly, with Annexes, United Nations, E 94 IX 11, New York.

UNSCEAR (2000) United Nations Scientific Committee on the Effects of Atomic Radiation, Sources, effects and risks of ionising radiation, Report to the General Assembly, with Annexes, United Nations, New York. 
Van Kaick G., Wesch H., Luhrs H., Lieberman D., Kaul A. (1991) Neoplastic diseases induced by chronic alpha irradiation. Epidemiological, biophysical and clinical results by the German Thoratrast study group, J. Radiat. Res. 32(Suppl 2), 20-33.

Vilenchik M.M., Knudson A.G. (2000) Inverse radiation dose-rate effects on somatic and germ-line mutations and DNA damage rates, Proc. Natl. Acad. Sci. USA 97, 5381-5386.

Vilenchik M.M., Knudson A.G. (2003) Endogenous DNA double strand breaks: Productio, fidelity of repair, and induction of cancer, Proc. Natl. Acad. Sci. USA 100, 12871-12876.

Vilenchik M.M., Knudson A.G. (2006) Radiation dose-rate effects, endogenous DNA damage, and signaling resonance, Proc. Natl. Acad. Sci. USA 103, 17874-17879.

Wakeford R., Little M.P. (2003) Risk coefficients for childhood cancer after intrauterine irradiation: a review, Int. J. Radiat. Biol. 79, 293-309.

Wang Z.Y., Boice J.D., Wein L.X. (1990) Thyroid nodularity and chromosome aberration among women in areas of high background radiation in China, J. Natl. Cancer Inst. 82, 478-485.

Wang J.X., Zhang L.A., Li B.X. et al. (2002) Cancer incidence and risk estimation among medical Xray workers in China 1950-1995, Health Phys. 82, 455-466.

Wei L., Sugahara T. (2000) An introductory overview of the epidemiological study on the population at the high background radiation areas in Yangjiang, China, J. Radiat. Res. (Tokyo) 41, 1-7.

Yang F., Stenoien D.M., Strittmatter E.F. et al. (2006) Phosphoproteome profiling of human skin fibroblast cells in response to low- and high-dose irradiation, J. Proteome Res. 5, 1252-1260.

Zeeb H., Blettner M., Langner I. et al. (2003) Mortality from cancer and other causes among airline cabin attentants in Europe: a collaborative study in eight countries, Am. J. Epidemiol. 158, 35-46. 